\title{
THE EFFECT OF SERVICE INSTALLATIONS ON STRUCTURAL INTEGRITY OF SLABS IN BUILDINGS
}

\author{
Ladislaus Lwambuka \\ P.O. Box 35131, Dar es Salaam \\ Tel: +255754265365 \\ Email:lwambuka@ce.udsm.ac.tz
}

\begin{abstract}
In building construction industry service installations, usually housed in conduit pipes, are commonly mounted inside reinforced concrete structural elements. This practice is adopted to attain aesthetical outlook at both interior and exterior surfaces of the buildings. Depending on the extent of service installations, the cross sectional area of the load bearing structural member is substantially reduced. However, the current structural design guidelines have no provision to accommodate the extent to which the existence of conduit pipes impairs the load bearing capacity of the structural element though reduced cross sectional area. This study has attempted to address this gap in structural design of buildings; it involves assessing the current design practice of considering a structural element as a full solid body and comparing its ultimate load bearing capacity with the ones containing the conduit pipes. The study findings are based on test results from laboratory experiments on reinforced concrete slab models with varying intensity of conduit pipe installations as commonly practiced on construction sites. Recommendations are put forth when and how to consider the reduced load bearing capacity through the existence of service installations as part of structural engineering designs.
\end{abstract}

Keywords: Design loads, Failure loads, service installations, conduit pipes

\section{INTRODUCTION}

\section{General}

In normal building construction processes the installation of services in the buildings needs the fixation of hollow tubes within the concrete structural element section. It is obvious that these installations occupy certain percent of structural area that was originally designed as part of the concrete structural element.

Depending on the percentage cross sectional area reduced due to provision of hollow tubes, the structural element may fail below the designed ultimate load because in normal design practices, the structural design guidelines take no cognizance of the reduced structural area.

\section{Definition of the problem}

For esthetical reasons installations of service provisions in the buildings have to be embedded within the structural elements; correspondingly the cross sectional area is reduced. A random survey of construction sites in Dar es Salaam revealed the common practice that conduit pipes are massively used to protect electrical wiring installations. To which extent the bearing capacity of the concrete structural element is impaired through the reduced cross sectional area is not taken care of at design stage. This study is attempting to design a mechanism of addressing this gap in structural engineering design of reinforced concrete structures. 


\section{Objectives}

The general objective of the study is to establish the effect of service installations on structural integrity of buildings

The specific objectives pursued in this study are as follows:

(a) To establish the magnitude of the problem.

(b) To study on how structural element behaves under loading with the reduced cross section area due to provision of hollow tubes.

(c) To establish when and how the design of reinforced concrete structural elements can be modified to accommodate the existence of hollow tubes.

\section{Methodology}

The methodology adopted was threefold; 1) to produce a reinforced concrete solid slab panel and design to establish the ultimate load, 2) to cast and test reinforced concrete slab panels with varying intensity of hollow tubes to establish the failure loads, and 3) to propose structural design modifications, as and where the existence of hollow tubes necessitates this action to address the reduced load bearing capacity of structural elements. 
Structural design of slab panel models DESIGN SHEET.

\begin{tabular}{|c|c|c|}
\hline Reference & Calculations & Output \\
\hline & 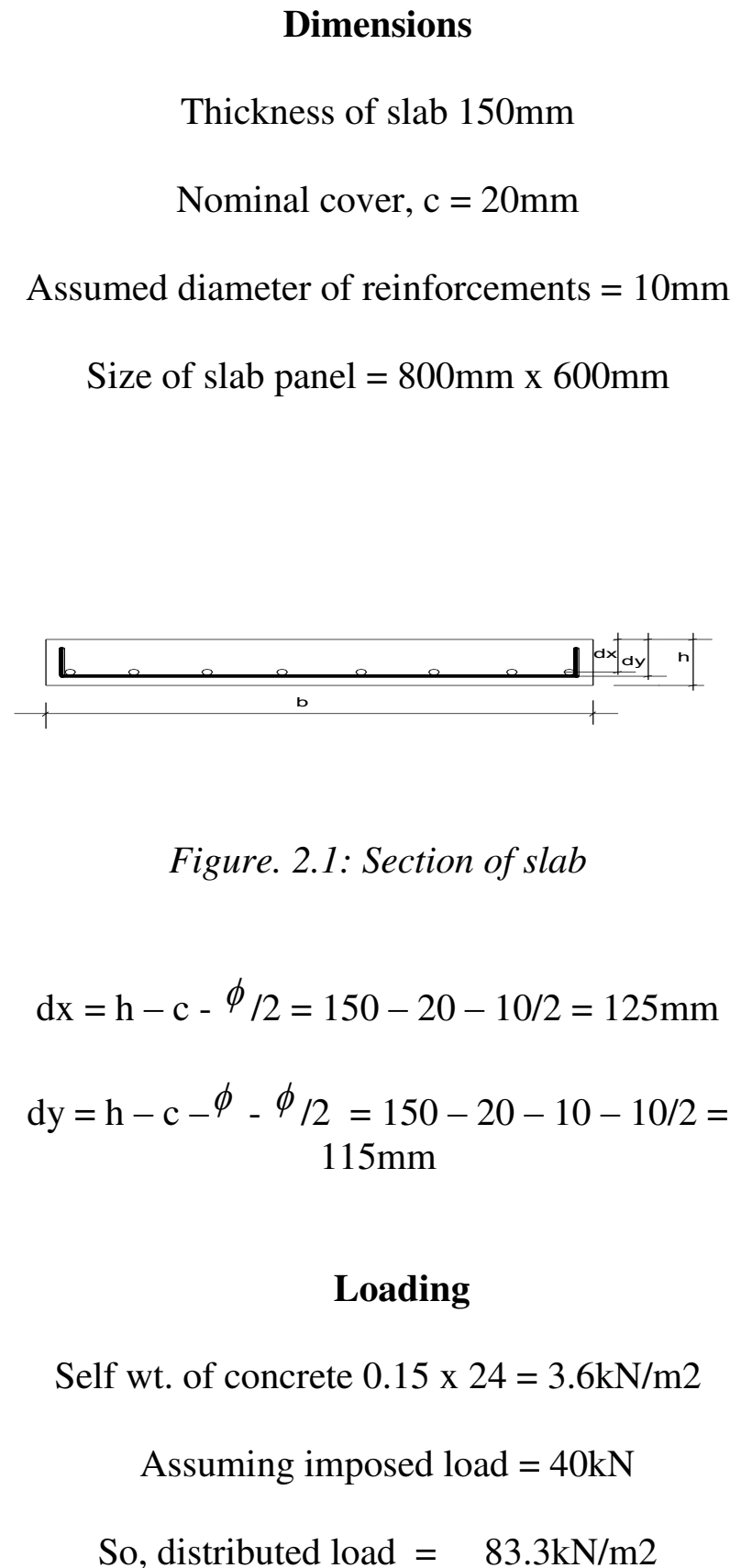 & \\
\hline
\end{tabular}


Table 3.13 BS 8110 Part I, 1997

Table 3.27 BS 8110 Part I, 1997
Ultimate load, $n$

$$
\mathrm{n}=1.4 \mathrm{gk}+1.6 \mathrm{qk}
$$

$=1.4 \times 3.6+1.6 \times 83.3=138.3 \mathrm{kN} / \mathrm{m} 2$

\section{Design moment coefficient}

$$
\begin{aligned}
& \alpha_{s x}=0.062 \\
& \alpha_{s y}=0.062
\end{aligned}
$$

Moments

$$
M_{s x}=\alpha_{s x} n l x^{2}=0.093 \times 138.3 \times 0.6^{2}
$$

$$
M_{s y} \equiv \alpha_{s y} n l x^{2} \equiv 0.051 x 138 .{ }^{3} \text { х } 0.62
$$

\section{Design of reinforcements}

$$
\begin{gathered}
\mathrm{Kx}=\frac{M_{s x}}{b d_{x}^{2} f_{c u}}=\frac{4.63 \times 10^{6}}{800 \times 125^{2} \times 25} \equiv 0.01 \\
Z x=\mathrm{d}\left(0.5+\sqrt{0.25-\frac{0.01}{0.9}}\right)=0.989 d>0.95 d
\end{gathered}
$$

take $Z x=0.95 d=0.95 \times 125$

\section{Area of reinforcements}

$$
\begin{gathered}
A_{s}=\frac{M_{s x}}{0.87 f y z x} \quad \text { take } \mathrm{fy}=250 \mathrm{~N} / \mathrm{mm} 2 \\
A_{s}=\frac{4.63 \times 10^{6}}{0.87 \times 250 \times 109.3}=194 \mathrm{~mm}^{2}
\end{gathered}
$$

\section{Minimum area of reinforcements}

$$
\frac{100 A_{s}}{A_{\mathrm{c}}}=0.24
$$

$$
A_{s \min }=\frac{0.24 \times 800 \times 150}{100}=288 \mathrm{~mm}^{2}
$$

$\mathrm{n}=138.3 \mathrm{kN} / \mathrm{M} 2$

Msy $=4.63 \mathrm{kNM}$

$\mathrm{Msx}=4.51 \mathrm{kNM}$

$Z x=109.3 \mathrm{~mm}$

Try $4 R 10-$ both way

$$
A_{s} \equiv 314 m m^{2}
$$




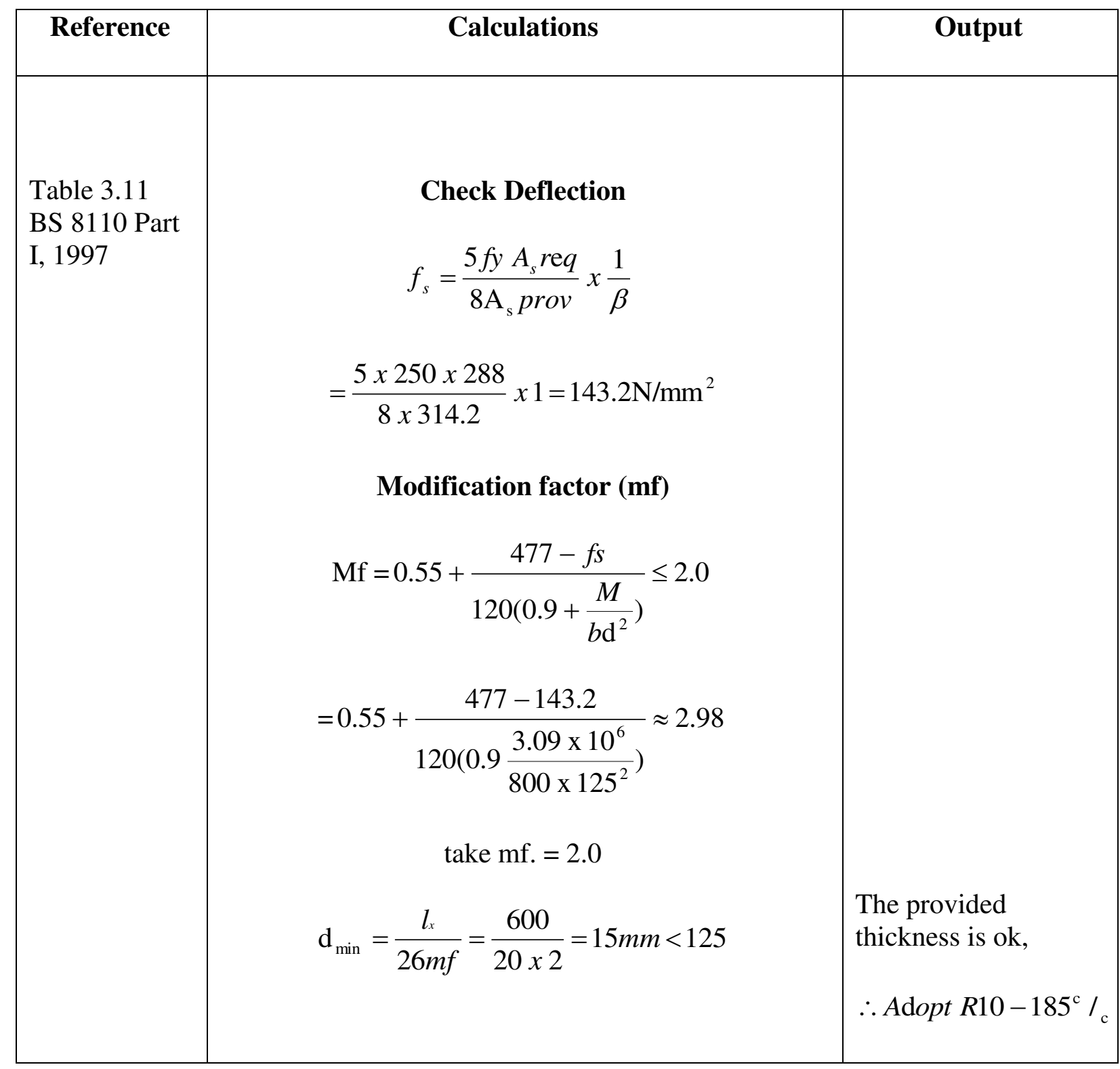




\section{Casting and testing of slab models}

Five pairs of slab panel models pairs were designed to represent typical floor slabs of the dimensions $800 \mathrm{~mm} \times 600 \mathrm{~mm} \times$ $150 \mathrm{~mm}$; to capture relevant slab design scenarios under normal loading; namely:

(i) A full solid slab panel

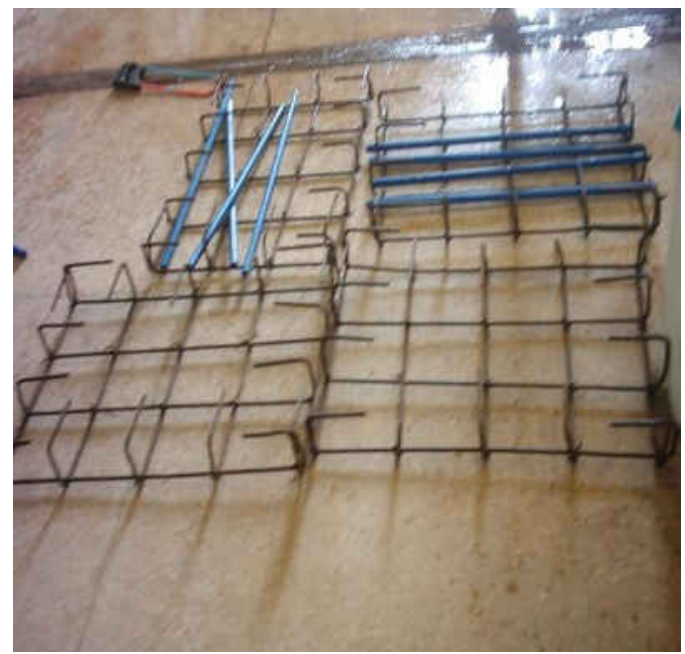

(a) (ii) A slab panel with a provision of two hollow tubes

(iii) A slab panel with a provision of four hollow tubes

(iv) A slab panel with a provision of six hollow tubes

(v) A slab panel with a provision of eight hollow tubes

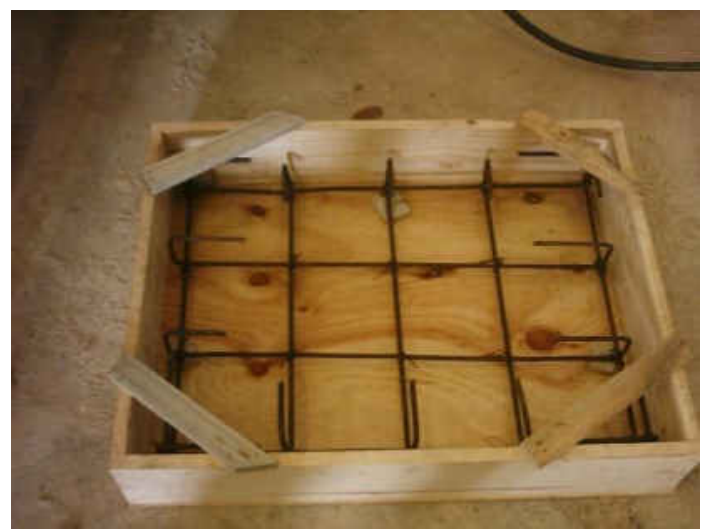

(b)

Figure 1a \&b: Preparation process of slab models

A Total of 10 slab models were prepared (Figure. $1 \mathrm{a} \& \mathrm{~b}$ ) and tested after 28 days of curing. The conduit pipes were provided at

different ranges as shown below in Table 1 and Figure. 2.

Table 1: Cross sectional areas of slab models

\begin{tabular}{|c|c|c|c|l|c|}
\hline Pair & $\begin{array}{l}\text { Number of } \\
\text { slab panels }\end{array}$ & $\begin{array}{l}\text { Number of } \\
\text { hollow tubes }\end{array}$ & $\begin{array}{l}\text { Occupied area } \\
\text { by pipes } \\
{\left[\mathrm{mm}^{2}\right]}\end{array}$ & $\begin{array}{l}\text { Cross section area of } \\
\text { slab } \\
{\left[\mathrm{mm}^{2}\right]}\end{array}$ & $\begin{array}{l}\% \text {-ge } \\
\text { occupied }\end{array}$ \\
\hline 1. & 2 & 0 & 0.0 & $1200 \times 10^{2} \mathrm{~mm}^{2}$ & 0.00 \\
\hline 2. & 2 & 2 & 628.4 & $1200 \times 10^{2} \mathrm{~mm}^{2}$ & 0.52 \\
\hline 3. & 2 & 4 & 1256.6 & $1200 \times 10^{2} \mathrm{~mm}^{2}$ & 1.05 \\
\hline 4. & 2 & 6 & 1885 & $1200 \times 10^{2} \mathrm{~mm}^{2}$ & 1.57 \\
\hline 5. & 2 & 8 & 2513.3 & $1200 \times 10^{2} \mathrm{~mm}^{2}$ & 2.09 \\
\hline 6. & & & & & \\
\hline
\end{tabular}




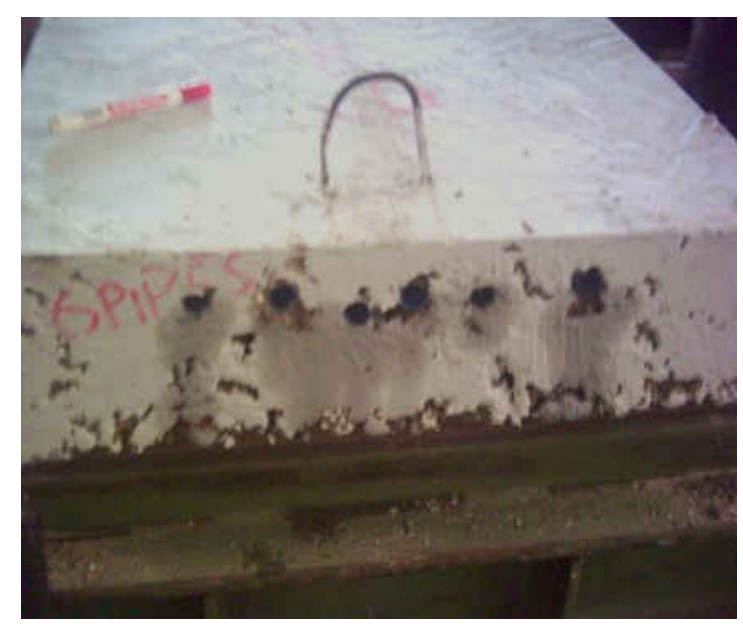

Figure 2: A Slab model with hollow tubes in the section

\section{TESTING OF SLAB MODELS AND RESULTS}

Slab models were tested in bending as shown in Figure. 3 and Figure. 4. The test machine was arranged to provide a simple support to the slab. The slabs were subjected to gradual load increment and the critical (failure) load was established. This was portrayed by the on-set of cracks preceded by maximum loading display on the dial gauge. The applied maximum loads were then recorded from the dial gauge. The results are shown in Table 2 .

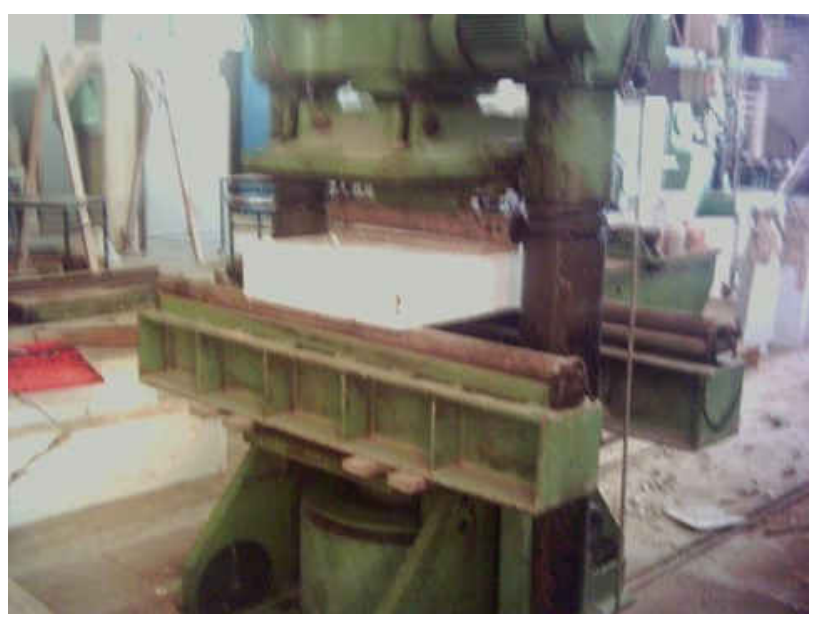

Figure 3: Testing procedure of slab models

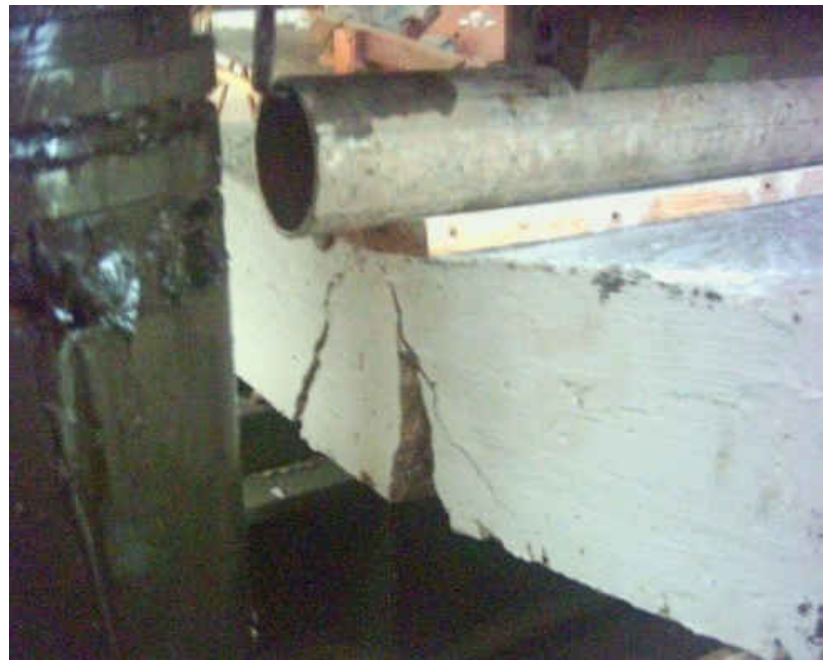

Figure 4: Failure mode of slab models under loading. 
Table 2: Test results of slab model

\begin{tabular}{|c|c|c|c|c|c|}
\hline \multirow{2}{*}{$\begin{array}{l}\text { Number of } \\
\text { slab panel } \\
\text { modals }\end{array}$} & \multirow{2}{*}{$\begin{array}{l}\text { Number of } \\
\text { conduit } \\
\text { pipes } \\
\text { provided } \\
\text { in each } \\
\text { panel }\end{array}$} & \multirow{2}{*}{$\begin{array}{l}\text { Estimated } \\
\% \text { ge of } \\
\text { reduction } \\
\text { in area }\end{array}$} & \multicolumn{3}{|c|}{ Recorded failure loads (kN) } \\
\hline & & & Test 1 & Test 2 & Average \\
\hline 2 & 0 & 0.0 & 76 & 72 & 74 \\
\hline 2 & 2 & 0.52 & 73.5 & 72 & 73 \\
\hline 2 & 4 & 1.05 & 71 & 70 & 70.5 \\
\hline 2 & 6 & 1.57 & 67 & 65 & 66 \\
\hline 2 & 8 & 2.09 & 59.5 & 60 & 60 \\
\hline
\end{tabular}

\section{ANALYSIS AND DISCUSSION OF}

\section{TEST RESULTS}

Basing on the test results, it reveals that the failure load decreases with the increase in reduction of area in the structural element of the concrete section.

The analysis is captured in Table 3 and Figure. 5 by looking comparably at the effect of reduced cross sectional area to the design value.

Table 3: Comparison between the design and failure loads at different reduction of section area

\begin{tabular}{|c|c|c|c|l|}
\hline $\begin{array}{c}\text { Test } \\
\text { No. }\end{array}$ & $\begin{array}{c}\text { \%ge } \\
\text { reduction } \\
\text { in area }\end{array}$ & $\begin{array}{c}\text { Design load } \\
\text { Converted to point } \\
\text { load) kN }\end{array}$ & $\begin{array}{c}\text { Failure } \\
\text { load kN }\end{array}$ & \multicolumn{1}{|c|}{ Remarks } \\
\hline 1 & 0.0 & 66.4 & 74.0 & No effect \\
\hline 2 & 0.52 & 66.4 & 73.0 & No effect \\
\hline 3 & 1.05 & 66.4 & 70.5 & No effect \\
\hline 4 & 1.57 & 66.4 & 66.0 & $\begin{array}{l}\text { Failure load close to } \\
\text { design load }\end{array}$ \\
\hline 5 & 2.09 & 66.4 & 60.0 & $\begin{array}{l}\text { Failure load lower than } \\
\text { the ultimate design load. }\end{array}$ \\
\hline
\end{tabular}




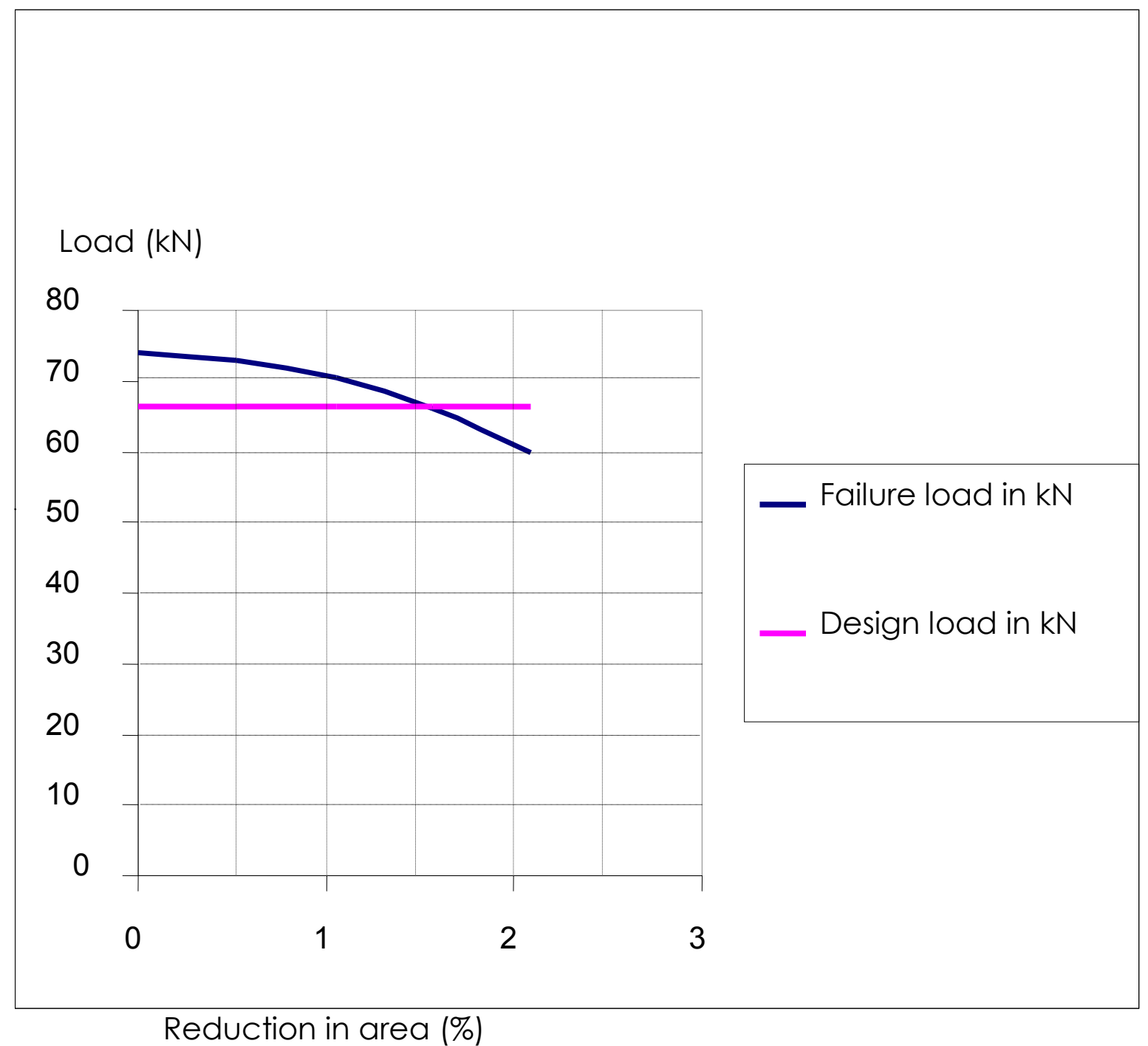

Figure 5: Comparison between the design and failure loads at different reduction of section area

\section{CONCLUSION}

The foregoing analysis reveals that the effect is not significant when the deducted area is below $1.5 \%$ of the total section area; in which case the design protocol can be maintained. An increase of reduced area beyond $1.5 \%$ of the total section area through provision of hollow tubes demands a changed design load consideration.

\section{RECOMMENDATIONS}

On basis of the test results and analysis thereof two major recommendations are being forwarded as response to the existing gap in structural design to accommodate the existence of service installations.

The maximum limit of area to be occupied by hollow tubes, and these are:

(i) The maximum limit of area to be occupied by hollow tubes in concrete 
slab should be $1.5 \%$ of total cross section area.

(ii) In case the area to be deducted due to provision of hollow tubes is greater than $1.5 \%$ the following modification on design and checking equations should be made.

a). Equation for ' $K$ - value' (factor) should be modified as follows.

Basic equation: $\mathrm{K}=\mathrm{M} / \mathrm{bd}^{2} \mathrm{f}_{\mathrm{cu}} \ldots \ldots$ (1)

Where $\mathrm{M}=$ design moment

$\mathrm{b}=$ breadth of section

$\mathrm{d}=$ effective depth of section

$\mathrm{f}_{\mathrm{cu}}=$ strength of concrete.

The basic equation can be re-written as follows.

$$
k=\frac{M}{b d^{2} f_{c u}} \ldots
$$

$$
\text { but } d=h-c-\frac{\phi}{2}
$$

where $\mathrm{h}-$ total depth of section $\mathrm{c}$ - concrete cover to the reinforcements

$\phi$ - diameter of reinforcements

Using equation (2) to replace single ' $d$ ' in equation (1)

$$
k=\frac{M}{b\left(h-c-\frac{\phi}{2}\right) d f_{c u}}=\frac{M}{\left(b h-b c-b \frac{\phi}{2}\right) d f_{c u}}
$$

But $b h=$ total cross section area of structural element. Let this area be ' $\mathrm{A}_{\mathrm{c}}$ '

Therefore equation (2) can be re-written as follows

$$
k=\frac{M}{\left(A_{c}-b c-b \frac{\phi}{2}\right) d f_{c u}} .
$$

If hollow tubes are provided in the section ' $\mathrm{A}_{\mathrm{c}}$ ' will decrease to ' $\Delta \mathrm{A}_{\mathrm{c}}$ ' such that

$$
\Delta \mathrm{A}_{\mathrm{c}}=\mathrm{A}_{\mathrm{c}}-\mathrm{A}_{\mathrm{r}}
$$

Where, $\Delta \mathrm{A}_{\mathrm{c}}$ is actual cross section area of structural element after reduction of area occupied by hollow tubes.

$\mathrm{A}_{\mathrm{r}}$ the area occupied by hollow tubes.

Therefore the exact equation for $\mathrm{k}$ - value or factor under provision of hollow tubes in the concrete section can be modified and expressed as.

$$
k=\frac{M}{\left(\Delta A_{c}-b c-b \frac{\phi}{2}\right) d f_{c u}}
$$

It is evident from equation (4) that ' $\mathrm{K}-$ value' will increase with the increase of reduction in area, $A_{r}$

The increase of $K$ value will affect the 'moment arm' causing it to decrease hence increase of area of reinforcement or necessitating the provision of bars in compression zone in case $\mathrm{K}>\mathrm{K}^{\prime}$

\section{b) Equation for deflection (minimum depth equation)}

The minimum depth equation depends on the value of modification factor as stipulated in BS 8110 part 1: 1985 table 3.11

In case of provision of hollow tubes (area greater than $1.5 \%$ ) the modification factor equation should be modified as follows.

Modification factor $=$

$0.55+\left(\frac{477-f s)}{120\left(0.9+\frac{M}{b d^{2}}\right)} \leq 2.0\right.$

But $d=h-c-\frac{\phi}{2}$ 
So replacing single ' $d$ ' in equation (5)

Modification factor

$$
=0.55+\left(\frac{477-f s)}{120\left(0.9+\frac{M}{b\left(h-c-\frac{\phi}{2}\right) d}\right)} \leq 2.0\right.
$$

or

Modification factor $=$

$$
0.55+\left(\frac{\left.477-f_{s}\right)}{120\left(0.9+\frac{M}{\left(\Delta A_{c}-b c-b \frac{\phi}{2}\right) d}\right)} \leq 2.0\right.
$$

$$
\begin{aligned}
& =\quad \text { where, } \Delta \mathrm{A}_{\mathrm{c}}=\mathrm{A}_{\mathrm{c}}-\mathrm{A}_{\mathrm{r}}
\end{aligned}
$$

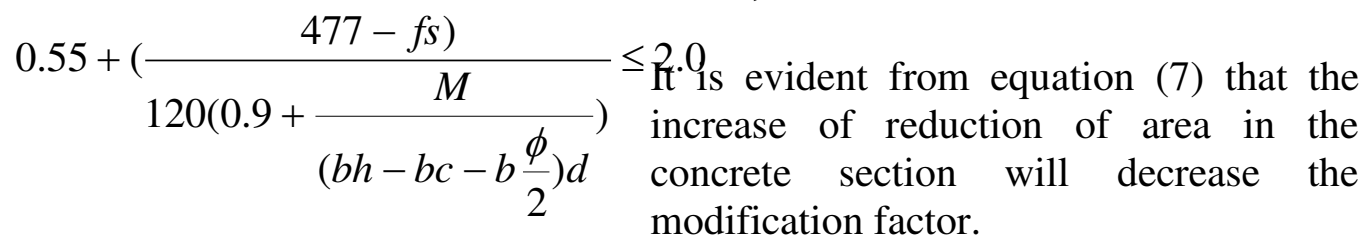

But bh $=\mathrm{A}_{\mathrm{c}}$

\section{REFERENCES}

So the modification factor can be rewritten as follows:

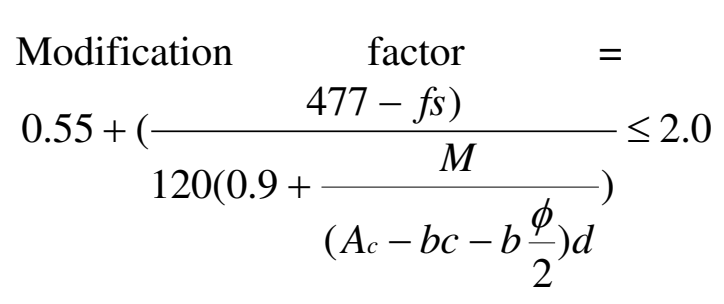

If the structural element is comprising the hollow tubes, the exact area of concrete section will be, $\Delta \mathrm{A}_{\mathrm{c}}$

So, equation (6) can be re-written as follows:
BS 8110: Part 1 (1985) Structural use of concrete Handbook to British Standard

Leonhardt, F. (1984) Vorlesungen über MassivbauTeil 1: Grundlagen zur Bemessung im Stahlbetonbau Springer Verlag

Mosley W. N.; Bungey J. H. (2008) Reinforced concrete design Macmillan Publishers Ltd.

Reynolds C. E.; Steedman J. C. (2005) Reinforced Concrete Designer's Handbook

Spon Press, Taylor \& Francis Group 